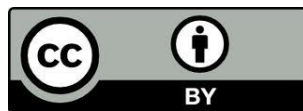

\title{
ESPACIALIDADE MORTUÁRIA: INTERACIONISMO SIMBÓLICO E REPRESENTAÇÕES RELIGIOSAS.
}

\author{
Spatiality Mortuary: Symbolic Interactionism Representations and Religious \\ Ana Helena Corrêa de Freitas GIL \\ Professora doutora em Geografia do Instituto Federal do Paraná Brasil. \\ e-mail: ana.gil@ifpr.edu.br
}

\author{
Sylvio Fausto GIL FILHO \\ Professor do Departamento de Geografia da Universidade Federal do Paraná - UFPR \\ - Brasil pesquisador do NEER e NUPPER \\ e-mail: faustogil@ufpr.br,
}

\begin{abstract}
RESUMO: O Interacionismo Simbólico parte do principio que os indivíduos agem a partir de seus significados, e o que as pessoas atribuem a eles. Pessoas e coisas viram desta maneira, um conjunto cultural, um palco onde se desenvolvem os cenários da interação. Nesse contexto, partimos da leitura sócio-interacionista de Erving Goffman (1985) que analisa o espaço, como um espaço de representações, onde cada indivíduo representa um papel, como se fosse em um teatro. A religião é parte estruturante das representações principalmente no que tange a condição da finitude humana e as interações sociais decorrentes da morte. A espacialidade mortuária se apresenta como palco privilegiado dessas relações. A partir do sentido peculiar das interações decorrentes da morte podemos perceber a própria dinâmica da vida. Cemitérios são lugares de estar-junto muito específico, porque se trata de um lugar de encontro entre a memória dos falecidos e dos vivos. Desenvolve-se, nesses lugares, mais do que em outras situações, todo um jogo de aparências, os mortos são simbolizados em diferentes épocas com diferentes formas e, nesse aspecto o mundo representacional da religião fornece um sentido específico para essa dinâmica. Para verificarmos as interações que ocorrem em cemitérios, analisamos um cemitério localizado na cidade de Curitiba - Paraná, o Cemitério Vertical de Curitiba.
\end{abstract}

Palavras-Chave: Interacionismo simbólico; Cemitério; Religião; representações.

ABSTRACT: Symbolic Interactionism part of the principle that individuals act from their meanings, and people attach to them. People and saw things this way, a whole culture, a stage where they develop scenarios of interaction. In this context, we start reading socio-interactionist Erving Goffman (1985) that analyzes the space as a space of representations, where each individual represents a role, like in a theater. Religion is part of the structural representations mainly regarding the condition of human finitude and death resulting from social interactions. Spatiality mortuary presents itself as a privileged these relationships. From the peculiar sense of the interactions arising from the death we see the dynamics of life. Cemeteries are places of being-together very specific, because it is a meeting place between the memory of the deceased and the living. It develops in these places than in other situations, an entire game appearances, the dead are symbolized in different times with different forms and in this respect the representational world of religion provides a sense specific to that dynamic. To study the interactions that occur in cemeteries, we analyze a cemetery located in the city of Curitiba - Paraná, Curitiba Vertical Cemetery.

Keywords: Symbolic Interactionism; Cemetery; Religion; representations. 


\section{Introdução}

O presente texto apresenta o cemitério como espaço dos vivos e dos mortos a partir do interacionismo simbólico de Erving Goffman a respeito das interações que ocorrem na espacialidade mortuária no caso do Cemitério Vertical de Curitiba- PR. Observamos no espaço do cemitério três tipos de palcos o primeiro realizado pelos funcionários e administrador, o segundo pelos familiares e conhecidos do falecido e, um último formado pelos vivos e a memória do falecido.

A interação entre os atores sociais caracteriza-se por uma performance galvanizada pelas representações religiosas enquanto expressas no mundo expressivo da morte. A religião esta sempre relacionada com a condição da finitude humana, neste caso não se trata de uma prática específica, pois estamos entendendo a religião como a forma com que as representações sociais no espaço mortuário são exercidas pelos atores sociais. Nosso pressuposto é que referencias religiosas são evocadas na tentativa de dar sentido a morte no palco do cotidiano.

\section{Interacionismo simbólico: notas teóricas}

A tendência do Interacionismo Simbólico surgiu como uma das correntes mais importantes da Escola de Chicago. Tal mudança dentro do conjunto da Universidade de Chicago pode ser interpretada como uma mudança da sociologia acadêmica durante os anos 1940, quando uma orientação cientifica, a qual depois da Primeira Guerra Mundial era ainda baseada no empirismo e positivismo que caminhou em direção de uma abordagem mais fenomenológica e dialógica. Como o termo "Interacionismo" deriva da palavra "interação" onde existe uma atividade compartilhada com trocas e influências recíprocas, a nova tendência refere-se ao estudo do comportamento coletivo e das regras de interação entre atores sociais.

O Interacionismo Simbólico parte do principio que os indivíduos agem a partir de seus significados, e o que as pessoas atribuem a eles. Pessoas e coisas viram desta maneira, um conjunto cultural, um palco onde se desenvolvem os cenários da interação.

Essa ideia vai ao encontro de toda uma conjuntura acadêmica que surgiu em diferentes regiões do mundo a partir da Primeira Guerra Mundial. Assim, por exemplo, na Rússia, Lev S. Vygotsky (1896-1934) afirmava que é fundamental que o indivíduo se insira num determinado meio cultural pré-existente para desenvolver sua trajetória social, sendo que essa inserção acontece através da linguagem e dos pensamentos. $\mathrm{O}$ 
individuo segundo Vygotsky adquire seus conhecimentos a partir de relações intra e interpessoais de troca com o meio. Tal inserção se desenvolve principalmente na fase da formação intelectual, ou seja, na infância, onde a influência cultural e social ocorre em maior peso em função da educação por família, escola e sociedade. O objeto de estudo de Vygotsky era o desenvolvimento humano a partir da compreensão de um processo histórico que o indivíduo estaria vivendo. O homem é assim nas relações sociais alguém que transforma e ao mesmo tempo é transformado. Em seu livro "A Formação Social da Mente", (2007) Vygotsky comenta que "as crianças pequenas dão nome aos seus desenhos apenas após terminá-los, precisam vê-lo para depois decidir o que são. Com idade mais avançada as crianças já mudam seu modo de ser, decidem previamente o que irão desenhar. Desse modo, começam a decidir e, ir além das experiências prévias, conseguem fazer uma imagem do futuro, o faz parte do seu ambiente imediato." (VIGOTSKY, 1987, p.31-33)

As ideias de Vygotsky diferem de Jean Piaget. Para ele quando uma pessoa entra em contato com um novo conhecimento acontece um desiquilíbrio, e a pessoa tem necessidade de voltar ao equilíbrio, para tal acontecer, é necessário um processo de acomodação, que leva a pessoa à organização interna e posterior equilíbrio.

Devemos lembrar que Piaget estudou a evolução do pensamento da criança até a adolescência procurando entender os mecanismos mentais que o indivíduo utiliza para captar o mundo, chamando isso também, de interacionismo.

O interacionismo abordado aqui é uma situação onde se estabelece um equilíbrio entre a assimilação e a acomodação, onde ocorre a adaptação e construção de esquemas, para se chegar ao equilíbrio seguindo a ideia de um construtivismo autônomo sequencial da criança. Assim, Piaget optou por uma perspectiva individualista, enquanto Vygotsky preferiu uma perspectiva coletiva.

O termo "interacionismo simbólico" se refere a uma combinação entre os dois elementos. Nele, nas interações entre os indivíduos desenvolvem-se comportamentos coletivos, mas aparecem numa forma individual. Assim, o modo como o indivíduo interpreta o mundo e o maneja torna-se o foco da investigação. Seu principal enfoque são os processos de interação que ocorrem entre as pessoas. Um ato simples, como comprar o pão matinal na panificadora, implica interpretar as ações dos outros, para se evitar choques nesse simples atos, as ideias de alimentação, de comércio, de 
reconhecimento social, todas elas estão presentes neste momento. E, claro que tais interações simbólicas devem ser sempre socialmente abertas e reconhecidas por parte dos membros da comunidade. Todavia, não podemos falar simplesmente de relações sociais fixas, como uma ação não adota meramente regras fixas, mas se baseia em definições aceitas recíprocas, trabalhadas e apenas depois estabelecidas em conjunto.

Observamos que o Interacionismo Simbólico surgiu como uma crítica às análises sociológicas que se preocupavam mais com as estruturas das organizações sociais. A nova abordagem destaca as interações, os quais ocorriam por causa das estruturas sociais, mas incluiriam também as atividades individuais. Tal resposta ao estruturalismo positivista na sociologia ganha um dos seus mais importantes representantes na figura de Erving Goffman. Brilhante aluno de Everett Hughes, o qual trabalhou sobre relações étnicas em Chicago, desenvolvia uma sociologia dramatúrgica fortalecendo a corrente de uma microssociologia sob o aspecto da representação teatral.

\section{A teoria sócio-interacionista de Erving Goffman}

Erving Goffman era filho de imigrantes judeus, nascido no Canadá em 1922, típico jovem gostava muito de ir ao teatro e ao cinema, se inspirando na sua evolução intelectual nas artes. Depois de ter terminado a escola, cursou a faculdade de química em 1939, mas só em 1944 teve a oportunidade de fazer o curso de seus sonhos: a Sociologia. Foi fortemente influenciado pelo pensamento de Emile Durkheim que considerava que o homem deveria ser preparado para a vida em sociedade. "A ação exercida pelas gerações adultas sobre as que ainda não estão maduras para a vida social, tem por objetivo suscitar e desenvolver na criança determinados números de estados físicos, intelectuais e morais que dele reclamam, por um lado, a sociedade política em seu conjunto, e por outro, o meio especifico ao qual está destinado." (DURKHEIM, 2002, p.44).

Após análises, Goffman concluiu que cada estudo deve ser considerado um sistema em si mesmo, uma ideia que veio fortemente influenciada pelo funcionalismo.

Desta maneira, partiu do pressuposto de que a sociedade funciona sistematicamente, se constituindo no exercício permanente de interações que ocorrem transmitidas pela linguagem e pela conduta, inclusive de gestos, olhares e outras formas de interação. Essa percepção interacionista da sociedade não só analisa as interações sociais destacando sujeitos, na grande maioria indivíduos, mas faz também uso da 
metáfora teatral por considerar pessoas como atores que se apresentam com suas atuações num teatro que podemos chamar "realidade". Goffman chega nessa proposição pela observação que a integração do mundo social acontece geralmente não tanto por individualidades autônomas, mas pela associação de papéis por cada indivíduo.

Mesmo assim, sua visão não se restringe aos papéis com funções fixas, pelo contrário, permite sempre portas abertas para o desenvolvimento de novos papéis e novas representações pelos indivíduos.

As relações entre os atores se dão pelos ritos organizados em interações cotidianas através da formação de papéis. O Eu social, que Goffman denomina o self, cria um território de papéis, um espaço pessoal, que cada um constrói cercando sua atuação.

Desse modo, sentar-se ao lado de outra pessoa em um banco de uma praça pode ser vivenciado pelo outro como uma intromissão ao espaço dele, criando um confronto de papéis com um resultado espacial. Evidencia-se, neste caso, que a junção de tais espaços "encenados" na realidade vivida necessita de negociações entre estes atores, essas podem acontecer através da obediência ou desobediência de regras ou tradições, sempre em comunicações imediatas.

A ideia da interação social influencia muito, até hoje, as mais diversas ciências sociais. Podemos considerar Goffman como um ícone nesses estudos. Ele faleceu em 1982, deixando um legado teórico e metodológico de inestimável importância. Este foi utilizado, entre outros, na psicologia social, na psiquiatria, na sociologia, na linguística aplicada, no direito e atualmente também na geografia.

A compreensão da sociedade no interacionismo simbólico tem sua base em ações, o método adotado por Goffman sempre é monográfico e empírico, ou seja, tratase de estudos de casos em profundidade sempre de pequenos grupos. Nesses grupos, o olhar se foca em observações e interpretações de representações das pessoas.

Necessita-se, como uma das principais características, a imersão do pesquisador nestas pesquisas. Neste contexto, a perspectiva interpretativa é fundamental durante a condução da pesquisa, porque deixa clara a subjetividade do pesquisador no evento da pesquisa (KAPLAN E DUCHON, 1988).

Trata-se, assim, de uma pesquisa qualitativa, na qual o pesquisador é um interpretador participante da realidade (BRADLEY, 1993), se apropriando do fenômeno 
social como um diretor (que dirige a pesquisa) junto com seus atores, assim, reproduzindo de certa forma uma peça de teatro. Consequentemente, se desenvolve a compreensão profunda do contexto social e cultural através de papéis e personagens e sua configuração, um ato que acontece paralelamente à própria construção da sociedade interacionista.

Dentro dessa perspectiva, Goffman abre também para a geografia um espaço teórico para o aperfeiçoamento de métodos de pesquisas qualitativas, quando parte do pressuposto que a interação social forma a construção de significados e representações em determinados espaços. Como refletimos em trabalhos anteriores "o espaço de representação refere-se a uma instância da experiência da espacialidade originária na contextualização do sujeito, trata-se de um espaço simbólico que perpassa o espaço visível e nos projeta no mundo. (Gil Filho, 2005, p.3)

O pesquisador pode considerar ambientes, como espaços sociais, onde o comportamento humano relaciona e configura grupos sociais. No ambiente, a copresença física do indivíduo é uma condição fundamental para a interação. Concreta no cotidiano.

Portanto, o interacionismo simbólico se preocupa basicamente com um conhecimento prático, analisando situações sociais, que se formam através de um acervo simbólico em palcos de atuação. Para isso é necessário identificar uma ordem estrutural das interações face-a-face. Neles, o indivíduo deve (ou não) aceitar regras, como se comunicar, fazer sua manifestação visual, ou movimentar o seu corpo. Desta maneira, segundo Goffman (1996, p.77), “o corpo possui uma simbologia comunicativa expressiva de um acontecimento e conhecimento social (postura, movimentos, atitudes...)".

$\mathrm{Na}$ análise da leitura sócio-interacionista, podemos conceber o espaço de um cemitério como um espaço performático de interação e de reflexão religiosa.

\section{A morte como finitude social no teatro da vida}

A morte enseja uma performance específica no espaço mortuário na medida em que atuamos em relação ao fato nesse palco privilegiado incorporando à dinâmica do cotidiano.

$\mathrm{Na}$ lembrança de Freud a ansiedade em relação à morte vem primeiro do medo de perder o outro e, ter que lidar com a questão da ausência. Só lembrando, que Freud 
perdeu pessoas que considerava importantes em sua vida como Jung e sua filha Sophie, vítima de gripe. Freud teorizou sobre a luta constante entre a força da vida e do amor contra a morte e a destruição, simbolizados pelos deuses gregos Eros (amor) e Tanatos (morte). A sua teoria da mente ganhou forma com a publicação em 1923, de "O Ego e o Id".

Goffman (1996) se refere aos enterros como um exemplo dos cenários que acompanham os atores, todo um ritual é necessário para a preparação do corpo que irá ser sepultado, o corpo é preparado, alguns utilizam vestimentas especiais de acordo com a religião que pertence.

No caso do cemitério vertical, as capelas com sofás embutidos já estão organizadas para receber os parentes do falecido e, para receber o caixão com o corpo. O caixão normalmente é utilizado aberto e o corpo coberto com flores, sendo fechado na hora do sepultamento. A Capela como palco, é um espaço de silêncio, sendo mantido por todos que participam desse cenário. Muitos participantes sofrem a perda de algum ente querido, outros se lembram de momentos de dor e, voltam-se a memória de suas emoções, revivendo as sensações que outrora sentiram. Sob o ponto de vista do dramaturgo Stanislavski (2008) a memória pode evocar sentimentos que você já experimentou, a dor de perder um ou amigo ou parente.

O ator de Stanislavski pode recapturar a emoção quando está completamente empenhado em seu papel e, “deve preocupar-se primordialmente, em descobrir métodos para criar um número infinito de combinações de almas humanas, caracteres, sentimentos, paixões para seus papéis." (STANISLAVSKI, 2008, p.261).

Em um velório as pessoas se vestem para a ocasião guardando a obrigatoriedade do luto, da roupa escura, da não utilização de pinturas ou acessórios extravagantes. $\mathrm{O}$ falar é sempre baixo em respeito ao falecido e a família, esses são alguns padrões considerados normais dentro de uma capela no cemitério vertical, diferente de outras culturas onde o sepultamento não é um motivo de sofrimento, mas, sim um motivo apenas de tristeza pela separação entre os que ainda estão vivos e os mortos.

No fundo todos sabem que a vida é frágil e, que mantemos a esperança de sermos expectadores da nossa própria morte, como já se referenciava Freud. Refletir sobre a morte é refletir sobre o desconhecido, é perder o comando da vida, o que pode causar a sensação de medo, pois pensar o desconhecido pode causar desconforto no 
cotidiano das pessoas, então "é melhor não pensar muito sobre essa questão", como afirma o diretor do cemitério vertical.

N. comenta que por ter um contato direto com a morte, não pensa muito sobre esse assunto, se sente realista, "a morte é algo que vai chegar para todos", a morte não lhe espanta, "sabe que acontece então não adianta ficar pensando muito".

Pensando a vida e a morte como um teatro, o dramaturgo Bertoldt Brecht vivenciou entre outros problemas do período de sua vida a questão da morte, o imperialismo decadente e o nascimento marcante do capitalismo, a divisão de classes, a ganância do homem sobre o homem, a saída das trincheiras de guerra, a matança dos semelhantes, do horror pós-guerra. Nesse contexto, conseguiu fazer do teatro um espaço para reflexão dessa temática sempre destacando a moral e os bons princípios. A morte, no caso das guerras, deveria servir como algo para ser analisada e, o teatro oferecido ao povo para que pudessem fazer uma análise de seus comportamentos ético e social.

O que podemos constatar é que a temática morte não é um dos assuntos que as pessoas gostam de conversar no seu cotidiano, pois trazem de volta sentimentos de saudades das pessoas que partiram, quer pela idade avançada, quer por doenças ou outros problemas.

A abordagem do cemitério visto como uma empresa como outra qualquer salientada pelo administrador do cemitério vertical é algo real, que todos acabaram vivenciando. Sem saber o dia certo para deixar esse mundo, o espaço em um cemitério é algo necessário para o sepultamento do corpo. Segundo o administrador "é um investimento que deve ser feito quando se está vivo." Uma propaganda dos carros utilizados pelos vendedores dos planos funerários do cemitério vertical, é o seguinte: Não tenha pressa, mas quando for vá de primeira. De forma criativa e, até mesmo considerada engraçada a propaganda do cemitério é realizada, como em qualquer outra empresa, o marketing ajuda nas vendas. "A vida cotidiana tem uma duração, um fluxo, mas não leva a parte nenhuma: o próprio adjetivo "cotidiano" e seus sinônimos indicam o tempo, neste caso, é constituído, é não só finita, mas irreversível, 'ser para a morte"” (GIDDENS, 2003, p.41). O tempo é o tempo do corpo aqui na Terra.

\section{O cemitério visto como um espaço performático de interação cotidiana}

Cemitérios são lugares de estar-junto muito específico, porque se trata de um 
lugar de encontro entre a memória dos falecidos e dos vivos. Desenvolve-se, nestes lugares, mais do que em outras situações, todo um jogo de aparências, como os mortos não aparecem mais, são simbolizados em diferentes épocas com diferentes formas.

Para verificarmos as interações que ocorrem em cemitérios escolhemos o Cemitério Vertical de Curitiba. (Figura 01)

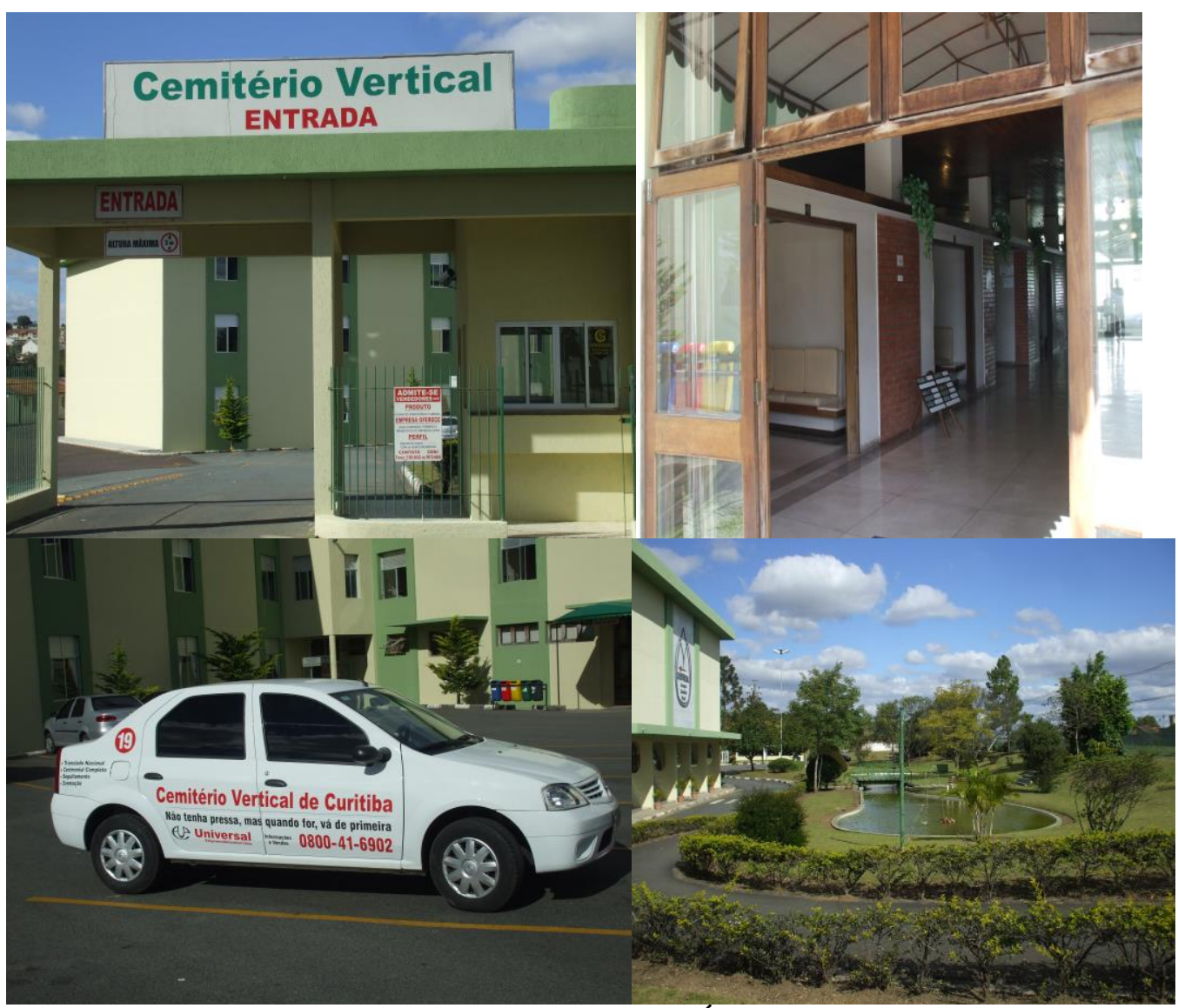

FIGURA 01 - O CEMITÉRIO VERTICAL FONTE: GIL, A.H.C.F, 2011.

De acordo com um dos administradores entrevistado, o Cemitério Vertical de Curitiba surgiu da ideia de alguns sócios, pertencentes à mesma família, que o projetaram e o instalaram com o objetivo de criar um espaço alternativo mortuário, dentro da cidade Curitiba - PR.

Com o passar do tempo, esse cemitério, tornou-se o maior cemitério vertical do mundo, devido o fato, que em poucos lugares existe esse tipo de serviço em prédios, onde os mortos são sepultados de forma diferenciada.

Trata-se de um cemitério cooperativo, onde os sócios (Ca. 30 mil pessoas), através de um plano de adesão, compram seu lugar de descanso. Os fundadores - 
diretores fizeram uma grande pesquisa dentro de Curitiba sobre o melhor local para ser implantado este cemitério, e também visitaram outros cemitérios em variados lugares para conceber o projeto, até que chegaram à construção deste cemitério no espaço do Tarumã, ao lado do Bairro Alto. O cemitério vertical segue toda a legislação de defesa dos solos, apesar de que, por ser vertical, nem precisaria disso.

O cemitério tem 24 anos e funciona como qualquer empresa com procedimentos comerciais. Possui 50 - 60 funcionários administrativos, além de 40-50 vendedores. Entre os funcionários encontram-se pedreiros, advogados, arquitetos, administradores de empresa, secretárias, entre outros. Como em ouras empresas do bairro, a rotatividade dos funcionários é baixa, e o primeiro funcionário registrado ainda continua trabalhado no cemitério.

Conforme o diretor: "As pessoas que trabalham no cemitério vertical de modo geral consideram um trabalho normal, como qualquer outro. É um ambiente de trabalho", como uma empresa comum; tem todo um trâmite a ser seguido, com regras e, muitos profissionais capacitados para desenvolvê-las".

O horário de funcionamento é de 24 horas, não fecha, mas claro que nem todos os funcionários ficam todo o período há uma espécie de rodízio ou escala. No cemitério são sepultados cerca de 80 corpos por mês, que são velados no mesmo local,em suas capelas que são em número de três.

Em Curitiba, em geral, os sepultamentos giram em torno de 350 por mês, o que significa que um pouco menos do que de toda a população morta da cidade está enterrado neste local. O cemitério vertical conta com um sistema de câmeras muito avançado.

As famílias que procuram o cemitério são de origens muito variadas, desde classes baixas, que procuram geralmente sepultamentos simples, até a classe alta, a qual se beneficia de áreas maiores e com mais detalhes, que são mais caras. O cemitério não possui sistema de cremação, mas recebe cinzas para serem guardadas em seu cemitério. Ainda, há um local próprio para o acendimento de velas, não perto dos sepultamentos dos mortos, evitando desse modo odores desnecessários ao longo dos corredores. Estes lugares são principalmente procurados para lembrar dos entes falecidos.

O diretor entrevistado possui uma sala isolada dos demais funcionários, sendo equipada com um insufilme escuro, o que permite que o diretor veja a ação de seus 
funcionários, no entanto, eles não enxergam o diretor. Esta determinação é necessária para manter uma atmosfera homogênea e de respeito no local.

O diretor é de sexo masculino, formado em arquitetura e administração, tem 32 anos. Reside num bairro próximo, não interage com outros moradores do bairro onde se localiza o cemitério, apenas trabalha no cemitério. Sua rotina normal de trabalhar começa pela manhã, depois ele vai para casa almoçar, volta trabalhar. Nos finais de semana, sua rotina é fazer esportes, ir ao clube encontrar alguns amigos.

$\mathrm{O}$ senhor $\mathrm{N}$. comenta que por ter um contato direto com a morte, não pensa muito sobre esse assunto, sente-se realista: "a morte é algo que vai chegar para todos, a morte não me espanta, sei que acontece, então não adianta ficar pensando muito". E assim, não mescla, numa ação de distanciamento (teatral) sua situação cotidiana da situação vivida no cemitério.

Isso demonstra como se desenvolvem no cemitério diferentes palcos. Um é o palco das relações de trabalho, através das interações entre os funcionários e a diretoria. Geralmente, procura-se manter uma relação cordial, para garantir uma atmosfera tranquila num ambiente onde as relações às vezes são tensas, devido aos sentimentos ligados ao impacto da morte de parentes e amigos. Por isso, o lugar se mantém bastante limpo e vazio, com poucos chamativos, e os funcionários fazem apenas conversas de voz baixa, ou ficam sem falar. Cria-se, assim, um ambiente de silêncio, um local próprio para meditação.

O segundo palco é da convivência entre os vivos. Para os visitantes cria-se a sensação de uma relação com os ausentes. Este palco do vazio se mostra ativo principalmente em datas específicos, como "finados", quando muitas pessoas costumam ir até o cemitério como uma forma de prestar uma homenagem ou demonstrar que não se esqueceram dos outros membros saídos da rede familiar ou de amigos.

Ainda tem um terceiro palco, este do próprio enterro, onde se destacam os falecidos. Goffman (1996, p.29) se refere aos enterros como um exemplo dos cenários que acompanham os atores. O palco da capela se junta ao palco da memória familiarsocial, sendo uma encenação religiosa. Cria-se aqui um espaço de silêncio, sendo mantido por todos que participam desse cenário. Água e cafezinho ficam à vontade para os clientes do local que conversam discretamente. Os participantes dessa cena sofrem a perda de algum ente querido, outros se lembram de momentos de dor e volta-se a 
memória de suas emoções, revivendo as sensações que outrora sentiram, o lugar é claramente um lugar de empatia emocional, enquanto existe um distanciamento vivido.

Tal empatia coincide com certa homogeneização através das tradições com os mortos. Assim, num velório, as pessoas se vestem para a ocasião guardando a obrigatoriedade do luto, com roupa escura. Geralmente, não utilizam maquiagem forte ou acessória extravagantes. Também, o falar é sempre baixo em respeito ao falecido e a família.

Percebemos que cemitérios são lugares específicos de encenações de pessoas que não são mais presentes. Assim, destacamos, além da exaltação dos mortos, a interação comunitária entre os familiares e amigos, a interligação funcional com os funcionários, e a interligação comercial com a empresa do cemitério. Ainda, esta esfera é muita interligada com os elementos religiosos, devido ao seu impacto profundo na filosofia cotidiana das pessoas.

\section{Considerações Finais}

De certo modo a morte funciona como uma estrutura estruturante de relações sociais específicas. Pois a interação simbólica diante da finitude humana, embora tenha seus aspectos valorativos intrínsecos, corresponde a um espaço performático em torno de ações significantes e cerimoniais. Nesse aspecto, os comportamentos religiosos são articulados na cena onde o ator desempenha aquilo que dele se espera no momento. $\mathrm{O}$ pesar, a possibilidade de transcendência a empatia com o sofrimento alheio fazem parte desse cenário montado para isso. O cemitério e as cerimonias fúnebres cumprem a função de desencadear essa performance já esperada. A trama de eterna repetição em torno da morte se faz como conformação simbólica da religião onde a radicalidade circunstancial da vida é expresso e rememorado.

\section{Referênciais}

BRADLEY, Jana. Methodological issues and practices in qualitative research. Library Quarterly, v. 63, n. 4, p. 431-449, Oct. 1993

BRECHT, B. A Música Gestus. Teatro Dialético, Rio de Janeiro: Civilização Brasileira, 1967, p.77.

.Escrito sobre teatro. Buenos Aires: Nueva Visión. 1970-1976.

.Estudos sobre teatro, Rio de Janeiro: Nova Fronteira, 2005. 
DURKHEIM, E. Lições de Sociologia. Trad. de STABEL, M. São Paulo: Martins Fontes, 2002. Sociologia e Filosofia, Trad. de MARTM, P. J.B, São Paulo: Icone, 1973.

GIL FILHO, S. F. Geografia Cultural: Estrutura e Primado das Representações. Espaço e Cultura. Rio de Janeiro: NEPEC, v.19-20, p.51-59, 2005.

GIDDENS, A.; TURNER, J.(org), Teoria Social Hoje. São Paulo: Editora da Unesp, 2006

GOFFMAN, E. A representação do eu na vida cotidiana. Trad. Maria Célia Santos Raposo. Petrópolis: Vozes, 1996.

JOAS, H. [1999]. Interacionismo simbólico. In GIDDENS, A.; TURNER, J.(org), Teoria Social Hoje. São Paulo: Editora da Unesp, 2006

KAPLAN, B. \& DUCHON, D.. Combining qualitative and quantitative methods in information systems research: a case study. MIS Quarterly, v. 12, n. 4, p. 571-586, Dec. 1988.

PIAGET, J. Psicologia e Pedagogia. Rio de Janeiro: Forense Universitária, 1985.

STANISLAVISKI, C. A preparação do Ator. Tradução de: PONTES L. Rio de Janeiro: Civilização Brasileira, 1976.

VYGOTSKI, L. A formação social da mente. São Paulo: Martins Fontes, 1987.

Recebido: $10 / 05 / 2012$

Received: 05/10/2011

Aprovado: 02/07/2012

Approved: 07/02/2012 